\title{
Characteristics of Word Fluency in Healthy Aging and Alzheimer's Disease
}

\author{
Mi Sook Lee ${ }^{1,2}$, Bo Seon Kim³ \\ ${ }^{1}$ Department of Audiology and Speech-Language Pathology, Hallym University of Graduate Studies, Seoul, Korea \\ ${ }^{2}$ HUGS Center for Hearing and Speech Research, Seoul, Korea \\ ${ }^{3}$ Department of Psychiatry, Incheon ST. Mary's Hospital, The Catholic University of Korea, Incheon, Korea
}

\section{정상 노인과 치매 환자의 단어유창성 특성}

\author{
이 미 숙,2.김 보 선 ${ }^{3}$
}

한림국제대학원대학교 청각언어치료학과 ${ }^{1}$, 한림청각언어연구소 ${ }^{2}$, 가톨릭대학교 의과대학 인천성모병원 정신과학교실

\begin{abstract}
Purpose: In general, aging factor or neurological disease degrades a function of working memory, leading poor word fluency. The purpose of this study was to investigate the characteristics of word fluency in healthy aging and Alzheimer's disease (AD). Methods: Nineteen healthy older adults, sixteen mild $A D$ and twelve moderate $A D$ subjects performed semantic and phonemic word fluency tasks. A series of cognitive-linguistic assessments were also administered to index working memory capacity, confrontation naming, attention, processing speed, and executive function as correlates of word fluency performance. Results: Findings indicated that the performances of word fluency differed significantly among three groups. In particular, all groups had better performances in semantic word fluency task. Mild and moderate $A D$ groups had significant differences in performances of semantic and phonemic word fluency. Word fluency were also significantly correlated with most cognitive-linguistic abilities in all groups. Executive function and working memory capacity were found to be the best predictors of word fluency. Conclusion: These results demonstrate that the performances of word fluency differed according to neurological aspects and severity of $A D$. In addition, the primary role of executive function and working memory capacity suggests the clinical usefulness of word fluency tasks in healthy aging and AD.
\end{abstract}

Key Words: Word fluency, Older adults, Alzheimer's disease, Cognitive-linguistic, Executive fnction.

Received: February 27, 2019 / Revised: March 26, 2019 / Accepted: March 29, 2019

Correspondence: Bo-Seon Kim, Department of Psychiatry, Incheon ST. Mary's Hospital, The Catholic University of Korea, 56 Dongsoo-ro, Bupyeong-gu, Incheon 21431, Korea

Tel: +82-32-280-5267 / Fax: +82-2-3453-6618 / E-mail: bskimslp@gmail.com

\section{INTRODUCTION}

단어유창성(word fluency)은 집행기능, 의미 처리 능력, 단어 지식을 평가하는 데 널리 활용되는 과제이다. 의미와 집행 처리 모두 단어유창성의 수행력에 관여하지만, 의미나 음운 범주 내 에서 단어를 산출하는 군집화(clustering) 과정, 효율적으로 새 로운 하위 범주로 이동하는 전환(switching) 과정이 독립적으 로 작용하기도 한다(McDowd et al., 2011). 예컨대, 노인은 전 환 과정이 원활하지 않으나 군집화는 젊은층과 유사하고, 분리

(c) This is an Open Access article distributed under the terms of the Creative Commons Attribution Non-Commercial License (https://creativecommons.org/licenses/by-nc/4.0) which permits unrestricted non-commercial use, distribution, and reproduction in any medium, provided the original work is properly cited.
주의력이 전환 과정에 영향을 미친다(Rosen et al., 2005).

노화와 신경학적 질환으로 인한 단어유창성의 저하는 언어 지식 자체의 손실이라기보다 전반적인 정보 처리 과정의 차원 에서 접근해야 한다. 즉, 정보 처리 과정에서 발생한 문제로 인 해 단기기억과 작업기억 능력이 저하됨으로써 단어유창성에 결 함이 나타난다(de Paula \& Malloy-Diniz, 2013; Vukovic et al., 2008). 따라서 작업기억이 매우 제한될 경우 의미적 및 음운적 재활성화가 요구되는 과제에서 전반적인 어려움을 보인다. 예컨 대, 노화나 신경학적 질환으로 인해 작업기억이 저하되면 단어 유창성 과제에서 산출하는 어휘의 양이 적을 뿐 아니라 어휘의 전형성과 효율적인 연상을 위한 반응 전략도 떨어진다 $(\mathrm{Un}-$ sworth et al., 2012). 특히, 작업기억 용량이 제한되는 후천적 
뇌손상 환자(acquired brain injury)는 의미적 단어유창성과 함 께 음운적 단어유창성이 저하된다는 보고도 있다(Marczinski \& Kertesz, 2006; Seniów et al., 2009).

수행 양상의 측면에서 젊은층은 단어유창성 과제의 수행력 이 높고 보속과 삽입이 거의 없는 반면, 노인은 정확도가 낮고 보속과 삽입이 많다(McDowd et al., 2011). 이는 노화가 작업기 억 용량과 집행기능에 부정적으로 작용하는 것과 연관된다. 신 경학적 질환군의 경우에도 집행기능과 작업기억은 단어유창성 의 수행력과 상관성이 크다. 과제 수행 시 무관한 정보가 유입 되지 못하게 하거나 이를 작업기억에서 삭제하기 위해서는 억제 (inhibition) 기능이 발휘되어야 하는데, 노화나 신경학적 질환 은 이 같은 기능을 방해한다(Peach \& Shapiro, 2012). 따라서 작업기억과 집행기능은 필연적으로 단어유창성의 수행에 부정 적으로 작용한다(Dennis \& Cabeza, 2008; McDowd et al., 2011). 예를 들어, 노인이나 알츠하이머병(Alzheimer's disease, $\mathrm{AD}$ ) 환자는 작업기억과 집행기능의 저하로 주의가 산만해질 뿐 아니라 한 과제에서 다른 과제로 빠르게 전환하기 어렵다. 또 한 이미 학습된 고정관념이나 경험적 지식, 도식에 지나치게 의 존한다. 그 결과, 음운적 및 의미적 단어유창성이나 대면이름대 기 과제에서 낮은 수행력을 보인다.

범주의 유형별로는 의미적 단어유창성(semantic word fluen$\mathrm{cy})$ 이 의미기억과 큰 상관성을 보이고, 음운적 단어유창성(phonemic word fluency)은 주로 어휘-음운기억(lexical-phonemic memory)의 영향을 받는다(Birn et al., 2010). 이에 따라 전자 는 측두엽의 기능을, 후자는 전두엽의 기능을 더 많이 요한다. 예컨대, 의미 체계 및 의미기억과 관련된 신경학적 네트워크에 기반한 수행력을 파악하기 위해서는 대면이름대기와 의미적 단 어유창성 과제를 활용한다. 이를 통해 측두엽의 기능 저하를 확인할 수 있기 때문이다. $\mathrm{AD}$ 는 초기부터 의미기억이 손상되 기 때문에 상대적으로 의미적 단어유창성의 수행력이 크게 저 하된다(Laatu et al., 2003). 이와 대조적으로, 전측두엽성 치매 (frontotemporal dementia)는 초기부터 음운적 단어유창성의 결함이 나타난다(Marczinski \& Kertesz, 2006). 실어증 환자 는 의미적 단어유창성보다 음운적 단어유창성 과제에서 더 높 은 수행력을 보이는데, 이는 음운적 단어유창성 과제가 의미 체 계에 대한 접근을 요하지 않기 때문이다(Seniów et al., 2009).

임상적인 측면에서 단어유창성은 의미 처리를 평가하는 데 유용하므로 노인 및 $\mathrm{AD}$ 환자의 인지-언어적 진단 도구로써 매 우 중요하다. 보편적으로 노화와 $\mathrm{AD}$ 로 인해 집행기능이 저하 되는 점을 고려할 때 단어유창성 과제의 임상적 유용성은 더욱 확대된다(Amieva et al., 2004). 집행기능은 다각적인 인지 처 리 과정을 요하는 고차원적 인지 영역이기 때문에 이에 대한 평가를 통해 여러 인지 및 언어 능력을 파악할 수 있다. 또한 일
상생활의 기능성을 발휘하는 데 결정적인 역할을 하므로 노인 및 신경학적 질환군의 삶의 질에 대한 매우 중요한 지표가 된 다(Royall et al, 2004). 집행기능에는 개념화에 따른 행동이 포 함되는데, 방해물의 차단, 주의 조절, 목표 지향적 행동에의 참 여, 요약, 문제 해결, 상위인지(metacognition), 행동 결과의 예 측 및 결과에 따른 재적응, 행동·진실성·의식의 시간적 통합, 정신적 유동성에 대한 적응의 개념 등 광범위한 능력을 요한다 (Peach \& Shapiro, 2012). 전술한 바와 같이, 작업기억과 집행 기능은 단어유창성과 직접적으로 연계되는데, 노화와 신경학 적 질환은 이 같은 과정에 부정적인 영향을 미친다(Andrés \& Van der Linden, 2002; Peach \& Shapiro, 2012).

이처럼 노화 및 신경병리학적 차원의 중요성이 대두되면서 단어유창성과 인지-언어 영역과의 상관성에 주목한 연구들이 증가하고 있다. 단어유창성을 수행하는 데 영향을 주는 인지언어적 변인들을 파악함으로써 신경학적 변화에 대한 진단적 역할을 명확히 규정할 수 있기 때문이다. AD 및 파킨슨병(Parkinson's disease) 환자군을 대상으로 단어유창성의 변인을 살 펴본 연구에서는, 집행기능이나 의미 지식보다 처리속도가 주요 한 인지-언어적 예측변인이었다(McDowd et al., 2011). Benja$\min$ et al.(2015)은 초기 $\mathrm{AD}$ 환자의 의미적 단어유창성이 자서 전적 기억(autobiographical memory)에 큰 영향을 미친다고 보 고했다. 실어증 환자를 대상으로 작업기억에 대한 중재를 실시 함으로써 단어유창성 능력이 향상되었다는 연구 결과도 있다 (Salis, 2012). 즉, 작업기억은 언어 처리 능력과 크게 연계되므로 작업기억의 향상은 언어 능력에 긍정적으로 작용한다(Seniów et al., 2009). 또한 전두엽 손상 및 전도성 실어증 환자들은 공통적 으로 음운적 단어유창성이 저하된다는 보고도 있다(Marczinski \& Kertesz, 2006; Seniów et al., 2009).

이 같은 결과들은 노화에도 유사하게 적용된다. 예컨대, 노인 은 작업기억의 용량이 제한적이기 때문에 복잡한 구문 구조를 표현하거나 이해하는 데 어려움이 있고, 주의 산만, 감각 상실, 이중 과제나 다중 과제의 요구도 영향을 미친다(Peach \& Shapiro, 2012). 여기에는 전전두피질(prefrontal cortex)의 기능 및 도파민 체계의 변화, 뇌 기능의 편재화(lateralization), 신경 조절 에 영향을 주는 뇌 구조 및 조직의 변화 등이 작용한다(Dennis \& Cabeza, 2008). 이에 근거하여 노인의 단어유창성 능력도 변 화한다. 처리속도와 억제는 노인의 단어유창성을 예측할 수 있 는 변인으로(Peach \& Shapiro, 2012), 이를 통해 단어의 인출 을 선택하고 집중하는 능력뿐 아니라 의미기억에서 정보를 인출 하는 속도가 단어유창성의 핵심 요소임을 알 수 있다. 즉, 처리 속도는 범주의 전환이나 군집화 능력에 크게 기여하는데, 이는 작업기억과 복합적으로 작용한다. 또한 처리속도는 집행기능 및 주의력과도 상관성이 높기 때문에(Signorini \& Volpato, 2006), 
억제성 기제가 원활히 발휘되지 못하면 과제 간의 빠른 전환 능력이 저하된다. 반면에, 인지 처리속도와 억제 능력이 고려될 경우 개인 차이에 따른 영향력이 최소화된다는 보고도 있다 (McDowd et al., 2011).

노화로 인한 단어유창성 능력의 저하는 많은 연구를 통해 보고된 바 있다. 연령이 높을수록 단어유창성 과제의 수행력이 저하되며, 이에 영향을 주는 변인으로는 성별이나 교육 수준 등 이 있다(Dennis \& Cabeza, 2008; Peach \& Shapiro, 2012). 노 인들이 특정 범주의 단어유창성 과제를 수행할 때 작업기억 용 량과 단어의 양보다는 인지 처리속도와 효율성의 영향을 더 크 게 받는다는 연구 결과도 있다(Peach \& Shapiro, 2012).

요컨대, 단어유창성은 의미 지식 이외의 인지-언어적 능력을 복합적으로 요하는 능력으로 노화 및 신경병리학적 차원에서 매우 유용한 진단적 기능을 할 수 있다. 따라서 정상 노인과 치 매 집단을 대상으로 단어유창성과 관련된 인지-언어 능력이 무 엇인지를 확인할 필요가 있다. 또한 단어유창성에 대한 인지언어적 예측변인을 파악함으로써 중재 과정에서 활용할 수 있 는 인지 및 언어 과제들을 증거 기반적으로 제시할 수 있다. 구 체적인 연구 문제는 다음과 같다.

첫째, 정상 노인, 경도 치매, 중등도 치매 집단 간에 단어유창 성의 차이가 있는가?

둘째, 각 집단별로 단어유창성과 인지-언어 능력 간에 어떠 한 상관성을 보이는가?

셋째, 각 집단별로 단어유창성을 예측하는 인지-언어적 변인 은 무엇인가?

\section{MATERIALS AND METHODS}

\section{연구 대상}

본 연구는 정상 노인 19 명과 경도 치매 환자 16 명, 중등도 치 매 환자 12 명 등 총 47 명을 대상으로 실시하였다. 정상 노인은 서울시 소재 노인정 3 곳으로부터 표집되었다. $\mathrm{AD}$ 환자는 서울 시 소재 노인복지관과 데이케어센터, 요양병원으로부터 표집되 었고, 신경과 전문의가 National Institute of Neurological and Communicative Disorders and Stroke and Alzheimer's Disease and Related Disorders Association (McKhann et al.,
1984)의 기준에 따라 $\mathrm{AD}$ 로 진단한 자를 대상으로 하였으며, Clinical Dementia Rating (CDR) (Morris, 1993) 척도에 따라 경도 $(\mathrm{CDR}=1)$ 집단과 중등도 $(\mathrm{CDR}=2)$ 집단으로 분류하였다.

노인 집단의 선정 기준에는 1) 만 65세 이상의 노인, 2) $\mathrm{Ko}^{-}$ rean-mini mental state examination (K-MMSE)의 정상군 규준(Kang, 2006)에 의거해 정상 범주에 속하는 노인, 3) 신경 학적 질환의 병력이 없는 노인, 4) 최소 6년 이상의 교육을 받은 노인이 포함되었다.

치매 집단은 1) 만 65세 이상으로, 2) $\mathrm{CDR}$ 에서 1 또는 2점으로 평가되고, 3) 신경과 전문의에 의해 $\mathrm{AD}$ 로 진단받았으며, 4) 최소 6년 이상의 학력을 가진 자로 선정하였다.

세 집단 간에 연령 $(\mathrm{F}=0.347, p=0.709)$ 및 성별 $\left(\chi^{2}=1.036\right.$, $p=0.596)$, 교육연수 $(\mathrm{F}=0.003, p=0.997)$ 의 분포상 유의미한 차이는 없었다.

대상군의 교육연수 기준은, 55세 이상의 후천성 뇌손상 환자 군의 인지-언어적 수행력이 6년 이상의 교육연수일 경우 유의 미한 차이가 없다는 연구 결과에 근거하였다(Lee, 2016). 연령, 성별, 교육연수, $\mathrm{K}-\mathrm{MMSE}$ 의 평균 및 표준편차 등 세 집단의 인구통계학적 특성은 Table 1에 제시하였다.

\section{연구 도구}

\section{단어유창성 평가}

의미적 단어유창성 과제로서 '동물'과 '과일’ 범주에 해당하 는 단어를 1 분 동안 최대한 많이 말하도록 하였다(Kang et al., 2000). 범주의 속성, 특히 생물과 무생물 범주에 따라 노인의 수행력이 크게 달라진다는 점을 고려하여 본 연구에서는 '생물' 범주만을 사용하였다(Laws et al., 2007).

음운적 단어유창성은 'ㄱ'과 'ㄴ으로 시작하는 단어를 1 분 동 안 말하도록 하는 과제로 평가하였다. 이는 한국 성인의 구어 및 사전 표제어상의 음소 빈도를 고려하여 선정하였다(Kang et al., 2000; Shin, 2008, 2010). 단어유창성을 평가하는 데 활용 된 과제 및 하위 영역은 Table 2와 같다.

\section{인지-언어 능력 평가}

단어유창성과 상관성을 갖는 관련 변인들을 알아보기 위해

Table 1. Group average and standard deviation for three groups as comparison of demographic characteristics

\begin{tabular}{lcccc}
\hline \multicolumn{1}{c}{ Characteristic } & Older adults $(\mathrm{n}=19)$ & Mild AD $(\mathrm{n}=16)$ & Moderate AD $(\mathrm{n}=12)$ & $p$-value \\
\hline Age (yr) & $74.53( \pm 7.14)$ & $76.38( \pm 4.57)$ & $75.42( \pm 9.17)$ & 0.709 \\
Gender (M:F) & $11: 8$ & $7: 9$ & $5: 7$ & 0.596 \\
Education level (yr) & $9.11( \pm 2.16)$ & $9.13( \pm 2.53)$ & $9.17( \pm 2.44)$ & 0.997 \\
K-MMSE & $26.63( \pm 1.89)$ & $18.94( \pm 3.71)$ & $14.17( \pm 3.49)$ & - \\
\hline
\end{tabular}

AD: Alzheimer's disease, K-MMSE: Korean-mini mental state examination 
Table 2. Evaluation of word fluency and other cognitive-linguistic abilities

\begin{tabular}{|c|c|}
\hline Domain & Task \\
\hline \multicolumn{2}{|l|}{ Word fluency } \\
\hline Semantic & Category: 'animal,' 'fruit' \\
\hline Phonemic & Letter: ‘ᄀ', ‘レ’ \\
\hline \multicolumn{2}{|c|}{ Working memory capacity } \\
\hline Digit span & Backward \\
\hline \multicolumn{2}{|l|}{ Confrontation naming } \\
\hline Picture/noun & K-BNT-15 \\
\hline \multicolumn{2}{|l|}{ Attention } \\
\hline Selective/divided & CAPTBI: selective/divided attention \\
\hline \multicolumn{2}{|l|}{ Processing speed } \\
\hline Cognitive processing & TMT: part A \\
\hline \multicolumn{2}{|l|}{ Executive function } \\
\hline Switching & TMT: part B \\
\hline
\end{tabular}

K-BNT-15: Short Form of the Korean version-the Boston Naming Test, CAPTBI: Cognitive-pragmatic language ability Assessment Protocol for Traumatic Brain Injury, TMT: Trail Making Test

5개 인지-언어 능력에 대한 평가를 시행하였다(Table 2). 즉, 노 화 및 신경학적 질환의 진전 과정에서 단어유창성의 수행력에 복합적으로 관여하는 작업기억 용량, 이름대기, 주의력, 처리속 도, 집행기능 과제를 선정하였다.

작업기억 용량(working memory capacity)은 숫자폭 검사 (digit span test) 중 숫자 거꾸로 따라말하기(digit backward)를 통해 분석하였다(Yeom et al., 1992). 대면이름대기 능력은 Short Form of the Korean version-the Boston Naming Test (K-BNT-15) (Kim \& Kim, 2013)로 평가하였는데, 흑백 선으 로 그려진 15 개 명사로 구성된 자극의 이름을 말하도록 하는 과제이다. 주의력은 Cognitive-pragmatic language ability Assessment Protocol for Traumatic Brain Injury (CAPTBI) (Lee, 2013)의 하위 영역 중 '선택주의력'과 '분리주의력'을 평가 하였다. 선택주의력은 다른 종류의 청각적 자극을 제시한 후 특 정 자극에만 반응하도록 하는 과제이며, 분리주의력은 시각적 및 청각적 자극을 동시에 수행하는 이중 과제로 구성된다. 처리 속도는 기호잇기검사(Trail Making Test, TMT) 중 숫자를 순서 대로 연결하는 과제인 'part A'로 평가하였다. 집행기능은 TMT 의 'part B'에서 알파벳을 한글 자음으로 교체한 검사를 적용하 였는데(Lee, 2013; Park \& Chey, 2003), 이는 숫자와 글자를 번 갈아 연결하는 과제를 수행하도록 요구한다.

\section{연구 절차}

정상 노인을 선별하고 치매 집단의 전반적인 인지 능력을 알 아보기 위해 1 차적으로 $\mathrm{K}-\mathrm{MMSE}$ 를 시행하였다. 선별된 노인 및 치매 집단을 대상으로 1 3회기에 걸쳐 단어유창성, 작업기 억 용량, 이름대기, 주의력, 처리속도, 집행기능을 평가하였다.
모든 검사는 소음이 최소화된 조용한 방에서 일대일 직접 평가 방식으로 진행되었고, 각 평가별 수행력에 대해 검사자가 기록 지에 기록하거나 피검자가 반응지에 직접 표기하도록 하였다.

채점 방식으로는, 단어유창성의 경우 제한된 시간(1분) 내에 각 범주 및 음소별로 산출한 단어의 평균 점수를 산정하였다. 즉, 의미적 단어유창성 과제는 2 개 범주에 대한 평균 단어 수 를 합산하여 총점으로 산정하였고, 음운적 단어유창성 과제는 2 개 음소에 대한 평균 단어 수를 합쳐 최종 점수로 사용하였 다. 숫자폭 검사는 피검자가 정확하게 수행한 단계의 숫자 자릿 수를 최종 점수로 간주하였고, $\mathrm{K}-\mathrm{BNT}-15$ 는 제한된 시간(30초) 내에 15 개 자극에 대해 자발적으로 정반응한 개수로 산정하였 다. $\mathrm{CAPTBI}$ 의 선택주의력과 분리주의력 과제는 정반응 개수 및 제한된 반응 시간에 따라 3 점 척도 $(2,1,0)$ 로 각각 채점한 후 두 점수를 합산하여 제시하였다. TMT의 part A와 part B는 검사 시작부터 완성 시까지의 시간(초)으로 점수를 산정하였다.

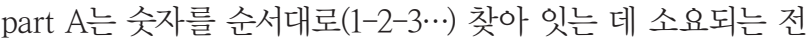
체 시간을, 그리고 part $\mathrm{B}$ 는 숫자와 한글 자음을 번갈아 가며 순서대로(1-ᄀ-2-ᄂ...) 연결하는 시간을 측정한 후 점수화하였 다. 따라서 반응 시간이 길수록 수행력이 낮음을 의미한다.

\section{통계 분석}

자료 분석을 위해 대상군에게 적용한 평가의 각 영역별 점수 를 산출하였다. 통계 분석 프로그램으로는 SPSS 21.0 version (IBM Corp., Armonk, NY, USA)을 활용하였다. 집단별로 연령 및 성별, 교육연수의 차이가 통계적으로 유의한지 알아보기 위 해 일원배치 분산분석(one-way ANOVA)과 카이제곱 검정 $\left(\chi^{2}\right.$ test)을 실시하였다. 기술통계 결과를 통해 세 집단의 단어유창 성 능력을 제시하였고, 일원배치 분산분석(one-way ANOVA) 과 사후 검증을 활용해 집단 간 수행력의 차이를 살펴보았다. 집단별로 단어유창성 과제와 다른 인지-언어 능력과의 상관성 을 알아보기 위해 피어슨 상관계수(Pearson correlation coefficient) 분석을 시행하였다. 또한 단어유창성에 대한 예측변인은 단계적 다중선형 회귀분석(stepwise multiple linear regression analysis)을 통해 알아보았다.

\section{RESULTS}

\section{단어유창성의 집단 간 차이}

정상 노인, 경도 치매, 중등도 치매 집단의 의미적 및 음운적 단어유창성 능력 간에 유의한 차이가 있는지 비교하였다.

의미적 단어유창성은 세 집단 간에 모두 유의미한 차이를 보 였다(F $=95.50, p<0.01)$ 음운적 단어유창성도 세 집단 간의 차이가 유의미하였다 $(\mathrm{F}=82.81, p<0.01)$. 즉, 의미적 단어유창 
성은 정상 노인의 수행력이 가장 높고, 중등도 치매 집단이 가 장 낮게 나타났다. 음운적 단어유창성도 정상 노인, 경도 치매, 중등도 치매 집단 순으로 수행력의 차이를 보였다. 세 집단 모두 에서 의미적 단어유창성의 수행력이 음운적 단어유창성에 비 해 높게 나타났다.

사후 검정 결과, 의미적 단어유창성은 정상 노인과 경도 $\mathrm{AD}$ $(p<0.01)$, 정상 노인과 중등도 $\mathrm{AD}(p<0.01)$, 경도 $\mathrm{AD}$ 와 중 등도 $\mathrm{AD}(p<0.05)$ 간에 유의한 차이가 있었다. 음운적 단어 유창성은 정상 노인과 경도 $\mathrm{AD}(p<0.01)$, 정상 노인과 중등도 $\mathrm{AD}(p<0.01)$, 경도 $\mathrm{AD}$ 와 중등도 $\mathrm{AD}(p<0.01)$ 간의 차이가 모두 유의미하였다.

세 집단의 단어유창성에 대한 수행력과 집단 간 비교는 Figure 1과 Table 3에 제시하였다. 세 집단의 5개 인지-언어 능력 에 대한 수행력은 Table 4에 추가하였다.

\section{단어유창성과 인지-언어 능력 간 상관성}

세 집단별로 단어유창성과 인지-언어 능력 간의 상관성을

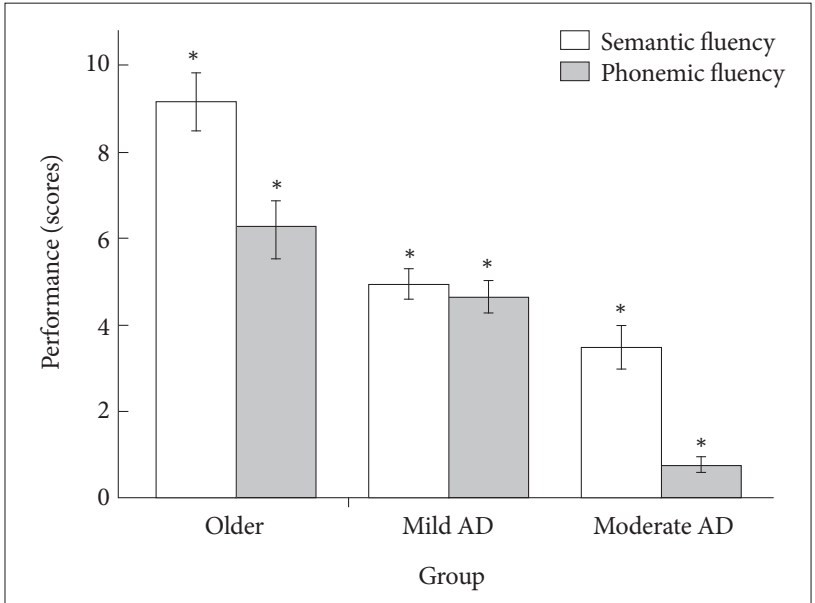

Figure 1. Semantic and phonemic verbal fluency performances in three groups. ${ }^{*} p<0.01$. AD: Alzheimer's disease.
알아보기 위해 상관 분석을 실시하였다,

정상 노인 집단의 의미적 및 음운적 단어유창성은 작업기억 용량, 대면이름대기, 주의력과 정적 상관 $(p<0.01)$ 을 보였고, 처 리속도 및 집행기능과 부적 상관 $(p<0.01)$ 을 나타내었다(Table 5). 경도 $\mathrm{AD}$ 집단에서도 의미적 및 음운적 단어유창성이 작업 기억 용량, 대면이름대기, 주의력과 정적 상관 $(p<0.01)$ 을, 처 리속도 및 집행기능과 부적 상관 $(p<0.01)$ 을 보였다(Table 6). 중등도 $\mathrm{AD}$ 집단의 경우 의미적 단어유창성은 작업기억 용량 $(p<0.05)$, 대면이름대기 $(p<0.01)$, 주의력 $(p<0.05)$ 과 정적 상 관을 보였고, 처리속도 및 집행기능과 부적 상관 $(p<0.01)$ 이 있 었다(Table 7). 반면에, 음운적 단어유창성은 작업기억 용량 $(p<0.05)$ 과 정적 상관을, 처리속도 $(p<0.05)$ 및 집행기능 $(p<$ $0.01)$ 과 부적 상관을 보였으나, 대면이름대기 $(p=0.054)$ 및 주 의력 $(p=0.071)$ 과는 유의한 상관성이 없었다.

\section{단어유창성의 예측변인}

세 집단에서 단어유창성의 예측변인을 분석한 결과는 Table 8에 제시하였다.

정상 노인 집단에서 의미적 단어유창성의 예측변인은 집행기 능 $\left(\mathrm{R}^{2}=0.77, \mathrm{~F}=56.45, p<0.01\right)$, 음운적 단어유창성의 예측 변인은 작업기억 용량 $\left(\mathrm{R}^{2}=0.65, \mathrm{~F}=31.52, p<0.01\right)$ 인 것으 로 나타났다. 또한 집행기능은 경도 $\mathrm{AD}$ 집단의 의미적 및 음운

Table 5. Correlation coefficient between word fluency and cognitivelinguistic ability in older adults group

\begin{tabular}{lcc}
\hline \multirow{2}{*}{ Cognitive-linguistic domain } & \multicolumn{2}{c}{ Word fluency } \\
\cline { 2 - 3 } & Semantic & Phonemic \\
\hline Working memory capacity & $0.868^{*}$ & $0.806^{*}$ \\
Confrontation naming & $0.874^{*}$ & $0.803^{*}$ \\
Attention & $0.665^{*}$ & $0.663^{*}$ \\
Processing speed & $-0.821^{*}$ & $-0.745^{*}$ \\
Executive function & $-0.877^{*}$ & $-0.805^{*}$ \\
\hline
\end{tabular}
${ }^{*} p<0.01$

Table 3. Comparison of group average and standard deviation for word fluency in three groups

\begin{tabular}{ccccccc}
\hline Word fluency & Older adults & Mild AD & Moderate AD & F & df & $p$-value \\
\hline Semantic & $9.21(0.96)$ & $4.94(1.49)$ & $3.50(1.19)$ & 95.50 & 2 & $0.000^{*}$ \\
Phonemic & $6.29(1.58)$ & $4.66(0.87)$ & $0.79(0.54)$ & 82.81 & 2 & $0.000^{*}$ \\
\hline
\end{tabular}

${ }^{*} p<0.01$. AD: Alzheimer's disease

Table 4. Comparison of group average and standard deviation for cognitive-linguistic abilities in three groups

\begin{tabular}{lcccc}
\hline Cognitive-linguistic domain & Older adults & Mild AD & Moderate AD & $p$-value \\
\hline Working memory capacity & $3.95( \pm 1.08)$ & $2.88( \pm 0.72)$ & $0.67( \pm 0.98)$ & $0.000^{*}$ \\
Confrontation naming & $11.89( \pm 2.21)$ & $9.75( \pm 2.38)$ & $4.42( \pm 1.78)$ & $0.000^{*}$ \\
Attention & $3.53( \pm 0.77)$ & $1.50( \pm 0.82)$ & $0.42( \pm 0.79)$ & $0.000^{*}$ \\
Processing speed & $33.74( \pm 9.25)$ & $83.75( \pm 15.55)$ & $188.75( \pm 82.89)$ & $0.000^{*}$ \\
Executive function & $43.95( \pm 7.20)$ & $100.50( \pm 13.54)$ & $214.67( \pm 49.11)$ & $0.000^{*}$ \\
\hline
\end{tabular}

${ }^{*} p<0.01$. AD: Alzheimer's disease 
적 단어유창성 $\left(\mathrm{R}^{2}=0.88, \mathrm{~F}=102.27, p<0.01\right)\left(\mathrm{R}^{2}=0.67, \mathrm{~F}=\right.$ $28.87, p<0.01)$ 과 중등도 $\mathrm{AD}$ 집단의 의미적 및 음운적 단어 유창성 $\left(\mathrm{R}^{2}=0.91, \mathrm{~F}=102.11, p<0.01\right)\left(\mathrm{R}^{2}=0.56, \mathrm{~F}=12.54\right.$, $p<0.01)$ 을 예측하는 공통적인 변인이었다.

\section{DISCUSSIONS}

본 연구에서는 정상 노인, 경도 치매, 중등도 치매 집단을 대 상으로 단어유창성의 수행력에 차이가 있는지 비교하고, 각 집 단별로 단어유창성과 인지-언어 능력 간의 상관성을 분석한 후 각각의 예측변인을 살펴보았다.

본 연구에서 의미적 및 음운적 단어유창성은 세 집단 간에 모두 유의미한 차이가 있었고, 정상 노인과 경도 $\mathrm{AD}$, 정상 노 인과 중등도 $\mathrm{AD}$, 경도 $\mathrm{AD}$ 와 중등도 $\mathrm{AD}$ 등 두 집단 간의 차 이도 모두 유의미하였다. 정상 노인과 $\mathrm{AD}$ 환자의 단어유창성 을 비교한 다른 연구에서, $\mathrm{AD}$ 집단은 보속과 삽입이 빈번하고 군집화와 전환이 적어 수행력이 유의하게 낮았다(McDowd et al., 2011). 본 연구와 마찬가지로 $\mathrm{AD}$ 의 중증도에 따른 수행력의 차이도 보고된 바 있다. 정상 노인과 경도인지장애(mild cognitive impairment, $\mathrm{MCI}$ ) 및 $\mathrm{AD}$ 의 언어 산출 양상을 비교한 연

Table 6. Correlation coefficient between word fluency and cognitive-linguistic ability in mild $A D$ group

\begin{tabular}{lcc}
\hline \multirow{2}{*}{ Cognitive-linguistic domain } & \multicolumn{2}{c}{ Word fluency } \\
\cline { 2 - 3 } & Semantic & Phonemic \\
\hline Working memory capacity & $0.800^{*}$ & $0.711^{*}$ \\
Confrontation naming & $0.802^{*}$ & $0.650^{*}$ \\
Attention & $0.738^{*}$ & $0.666^{*}$ \\
Processing speed & $-0.887^{*}$ & $-0.771^{*}$ \\
Executive function & $-0.938^{*}$ & $-0.821^{*}$ \\
\hline
\end{tabular}

${ }^{*} p<0.01$. AD: Alzheimer's disease

Table 7. Correlation coefficient between word fluency and cognitive-linguistic ability in moderate AD group

\begin{tabular}{lcc}
\hline \multirow{2}{*}{ Cognitive-linguistic domain } & \multicolumn{2}{c}{ Word fluency } \\
\cline { 2 - 3 } & Semantic & Phonemic \\
\hline Working memory capacity & $0.700^{*}$ & $0.625^{*}$ \\
Confrontation naming & $0.924^{\dagger}$ & 0.569 \\
Attention & $0.676^{*}$ & 0.538 \\
Processing speed & $-0.930^{\dagger}$ & $-0.658^{*}$ \\
Executive function & $-0.954^{\dagger}$ & $-0.746^{\dagger}$ \\
\hline
\end{tabular}

${ }^{*} p<0.05,{ }^{\dagger} p<0.01$. AD: Alzheimer's disease
구에 따르면, 정상 노년층의 단어유창성은 청·장년층에 비해 뚜 렷이 저하되며, $\mathrm{MCI}$ 역시 $\mathrm{AD}$ 와 유사한 정도로 낮은 수행력을 보인다(Lee \& Kim, 2011). 또한 $\mathrm{AD}$ 는 초기 단계부터 뚜렷한 저 하를 보이기 시작해 중증도가 심화될수록 더욱 두드러진다.

단어유창성과 인지-언어 능력 간의 상관성은 집단별로 다소 차이를 보였다. 정상 노인과 경도 $\mathrm{AD}$ 집단은 의미적 및 음운적 단어유창성이 작업기억 용량, 대면이름대기, 주의력, 처리속도 및 집행기능과 모두 상관성을 보였다. 또한 중등도 $\mathrm{AD}$ 집단의 의미적 단어유창성도 이들 영역과 모두 유의미한 상관관계가 있 었다. 단어유창성과 인지-언어 능력 간의 상관성은 연구마다 다 양하나, 특히 $\mathrm{AD}$ 환자의 단어유창성과 집행기능 간의 높은 상 관성을 강조한 보고들이 많다(de Paula \& Malloy-Diniz, 2013; Ivanoiu et al., 2006). McDowd et al.(2011)은 집행기능의 억제 과정이 정상 노인과 $\mathrm{AD}$ 환자의 단어유창성에 크게 기여한다고 보고했다. 집행기능은 $\mathrm{AD}$ 환자의 일상적 활동과 같은 기능적 인 수행력을 반영하는 핵심 요소이므로 작업기억을 포함한 여 러 인지-언어적 기제들 간의 관계를 다각적으로 고려해야 한다 (de Paula \& Malloy-Diniz, 2013). 이를 위해 의미적 및 음운 적 단어유창성 과제가 주로 활용된다. 예를 들어, 단어유창성 과제를 수행하기 위해서는 의미 지식을 기반으로 한 단어를 탐 색하고, 부적절하거나 규칙에 어긋나는 반복적인 반응을 억제 해야 한다. 이 과정을 통해 적절하고 연관성 있는 반응을 산출 하게 된다. 의미 지식이 고갈되면 전환이 일어나면서 이전의 경 험으로부터 새로운 항목들을 상기하도록 촉진한다(Benjamin et al., 2015). 이때 작업기억 용량은 의미 지식에 대한 전략적 탐 색과 관련되므로(Unsworth et al., 2012), 의미적 단어유창성과 직·간접적으로 연계된다.

집행기능과 단어유창성 간의 상관성에 관한 위 결과들과 마 찬가지로, 본 연구에서도 집행기능은 노인과 $\mathrm{AD}$ 환자의 단어 유창성에 영향을 주는 요인이었다. 특히, 노화와 초기 $\mathrm{AD}$ 단계 에서 집행기능이 의미적 단어유창성뿐 아니라 음운적 단어유 창성에도 관여한다는 사실은 주목할 만한 결과이다. 이는 노화 나 신경학적 질환의 진전을 늦추기 위한 예방적 조치에 있어 집 행기능과 의미적 및 음운적 단어유창성을 고려할 수 있는 임상 적 근거를 제공한다.

단어유창성 과제를 수행하는 데 있어 인지 처리속도가 우선 적으로 작용한다는 연구 결과도 많다(McDowd et al., 2011; Signorini \& Volpato, 2006). 이는 정상 노인과 $\mathrm{AD}$ 환자 모두

Table 8. Predictors of word fluency for three groups

\begin{tabular}{cllc}
\hline Word fluency & \multicolumn{1}{c}{ Older adults } & Mild AD & Moderate AD \\
\hline Semantic & Executive function & Executive function & Executive function \\
Phonemic & Working memory capacity & Executive function & Executive function \\
\hline
\end{tabular}

AD: Alzheimer's disease 
에 해당되는데, 특히 범주의 전환이나 군집화 능력에 큰 영향을 미친다. 이러한 인지 처리속도는 작업기억과의 연계 속에서 작 용한다. 처리속도는 작업기억의 근간을 이루는 기제로서 강조 된 바 있으며, 집행기능 및 주의력과도 상관성이 높다(McDowd et al., 2011). 즉, 억제성 기제가 제대로 작동하지 않으면 주의력 이 저하될 뿐 아니라 한 과제에서 다른 과제로 빠르게 전환하기 어렵다(Peach \& Shapiro, 2012). 노인들이 이미 학습된 고정관 념과 경험적 지식, 도식에 의존하는 성향을 보이는 것도 이와 동 일한 맥락이다. 따라서 정상 노인과 $\mathrm{AD}$ 환자의 단어유창성이 처리속도, 작업기억, 집행기능과 모두 연계된다는 본 연구 결과 역시 이 같은 관점에서 설명될 수 있다.

대면이름대기와 단어유창성 과제 간의 상관성은 $\mathrm{AD}$ 환자를 대상으로 보다 활발히 연구되어 왔다. $\mathrm{AD}$ 의 이름대기 능력은 신경학적 퇴행 과정에 따라 저하되며, 이는 대면이름대기와 단 어유창성에서 모두 입증되었다(Henry et al., 2004). Tchakoute et al.(2017)은 $\mathrm{AD}$ 의 의미 및 어휘 인출 능력을 살펴본 연구에 서 의미적 단어유창성과 대면이름대기 과제가 발병 후 1년 시점 의 전반적인 인지-언어 능력을 예측하는 요인임을 강조하였다. 또한 두 과제의 기초선 점수를 통해 $\mathrm{AD}$ 의 중증도를 예측할 수 있으나, 일상적인 기능을 반영하는 정도는 낮다고 지적했다.

한편, 본 연구에서 중등도 $\mathrm{AD}$ 집단의 음운적 단어유창성은 몇몇 변인들과의 상관성만 입증되었다. 이는 노인 및 $\mathrm{AD}$ 집단 의 의미적 단어유창성과 모든 인지-언어 능력 간에 상관성을 보인 것과 대조적이다. 보편적으로 의미적 단어유창성에 비해 음운적 단어유창성 과제의 수행력에 영향을 주는 변인들이 보 다 다양한 것으로 알려져 있다. 예를 들어, 교육 수준은 음운적 단어유창성의 수행력에 영향을 미친다(Choi, 2012). 어휘-음운 기억을 담당하는 전두엽의 손상 정도나 중증도에 따른 수행력 의 차이도 크다(Birn et al., 2010). 즉, 자서전적 기억, 일화기억 (episodic memory) 등 의미적 차원의 영향에 민감한 의미적 단 어유창성과 달리(Ivanoiu et al., 2006), 음운적 단어유창성에 관 여하는 인지-언어적 변인은 훨씬 다양하다(Ivanoiu et al., 2006). 따라서 통제 요인에 따라 음운적 단어유창성과 인지-언어적 변 인 간의 상관성이 다르게 나타날 수 있다.

본 연구에서 집행기능은 세 집단에서 공통적으로 단어유창 성을 예측하는 주요 변인이었다. 이는 집행기능과 단어유창성 이 상호 간의 수행력을 매우 유용하게 반영하는 진단적 과제로 서 활용될 수 있음을 의미한다. 보편적으로 집행기능의 평가는 복잡하고 다층적인 인지 처리를 요하기 때문에 '과제 불확실성 (task indeterminacy)'이라는 난제를 안고 있다(McDowd et al., 2011; Lee, 2016). 즉, 집행기능은 업데이트, 전환, 억제와 같은 하위 영역들이 상호 변별적으로 작용하며, 주의력의 할당과 선 택, 억제 과정이 연계되는 고차원적 인지기능을 요한다. 또한
집행기능을 반영하는 카드 분류나 단어유창성 과제의 수행력 이 추론력 및 지각 속도와도 높은 상관성을 보인다(Salthouse, 2005). 신경학적인 측면에서 전두엽이 손상되면 대부분 심한 집 행기능장애(executive dysfunction)가 나타나지만, 집행과 관련 된 처리가 항상 전두피질(frontal cortex)에서만 일어나는 것은 아니다(Andres \& Van der Linden, 2002). 사실상 뇌의 거의 모 든 영역이 집행기능장애와 연관된다. 이 같은 속성에 기반하여, 노인 및 $\mathrm{AD}$ 의 단어유창성을 평가할 때 집행기능을 함께 고려 할 필요가 있다. 본 연구를 통해 단어유창성이 정상 노인과 $\mathrm{AD}$ 환자의 집행기능과 상호 연계되는 영역임을 확인할 수 있었다.

본 연구에서 정상 노인의 음운적 단어유창성을 예측하는 또 다른 요인은 작업기억 용량이었다. 이는 단어의 양과 작업기억 용량이 노년층의 음운 인출 능력에 영향을 주지 않는다는 견해 (Peach \& Shapiro, 2012)와 배치된다. 노화로 인한 작업기억 용량의 저하는 단어유창성의 결함을 초래하는데 $(\mathrm{McDowd}$ et al., 2011), 이는 작업기억을 관장하는 전전두피질과 흑질선상체 (nigrostriatal)의 도파민 신경 전달 체계가 노화의 영향을 크게 받는다는 신경학적 속성에 근거한다(Raz, 2005). 보편적인 작 업기억 모델에는 시각 및 청각 정보를 저장하는 두 임시 저장 기제와 하나의 중앙 집행기, 장기기억과 관련된 임시 완충기 (episodic buffer)가 포함된다(Baddeley, 2000). 이러한 다영역 체계에 있어 정보를 임시로 저장하거나 처리 과제들 간에 주의 력을 분산시키는 데 필요한 용량은 제한적이다. 노화로 인해 작 업기억 용량이 감소하면 감각의 예민성과 관련된 신경 통합과 억제 기능이 떨어지면서 다영역 체계가 원활하게 작용하지 못 한다(Peach \& Shapiro, 2012). 이는 인지-언어 능력들 간의 탈 분화(differentiation)로 연계된다. 즉, 나이가 들수록 인지-언어 적 수행력 간의 차이가 없어지면서 서로 상관성이 높아지는데, 이로 인해 구어의 처리속도나 효율성이 떨어지게 된다. 본 연구 결과는, 노화로 인한 작업기억 용량의 저하가 다영역 체계의 결 함을 초래함으로써 음운기억과 음운적 재활성화에 기반한 음 운적 단어유창성의 수행에 부정적으로 작용함을 부분적으로 입증하였다.

본 연구의 임상적 의의는 다음과 같다. 첫째, 노화와 신경병 리학적 질환이 의미적 및 음운적 단어유창성의 수행력에 미치 는 영향을 증거 기반적으로 확인하였다. 둘째, 정상 노인 및 $\mathrm{AD}$ 환자의 중증도에 따라 단어유창성 능력을 실질적으로 파 악하고, 단어유창성에 영향을 주는 인지-언어 능력이 무엇인지 를 확인하였다. 셋째, 단어유창성이 집행기능, 작업기억 등 복합 적인 인지기능을 민감하게 반영하는 진단적 과제로서 유용함 을 입증하였다.

본 연구는 몇 가지 한계점을 갖는다. 첫째, 본 연구에서는 집 행기능의 특정 하위 영역에 국한된 평가를 시행하였다. 즉, 전 
환 능력에 중점을 둔 과제를 활용함으로써 집행기능의 다양한 속성을 고루 반영하지 못하였다. 단어유창성과 집행기능의 상관 성을 살펴본 많은 연구들에서 억제, 전환, 업데이트, 이중 과제 등의 하위 영역이 다양하게 고려된 바 있다(Hull et al., 2008; Salthouse et al., 2003). 추후 연구를 통해 집행기능의 하위 유 형별로 단어유창성과의 상관성을 살펴볼 필요가 있다. 둘째, 단 어유창성을 수행하는 데 요구되는 하위 과정들을 고려해야 한 다. 예컨대, 의미나 음운 범주 내에서 단어를 산출하는 군집화 과정, 새로운 하위 범주로 이동하는 전환 및 교대 과정에 따라 노인과 신경학적 질환군의 수행력이 어떻게 달라지는지에 대해 체계적이고 지속적인 검증이 요구된다. 셋째, 본 연구에서 입증 된 바와 같이 집행기능은 단어유창성의 가장 중요한 예측변인 이었다. 따라서 추후에는 집행기능의 속성을 실질적으로 반영 할 수 있는 과제를 다양하게 고려할 필요가 있다. 예를 들어, 일 상의 기능적 양상을 반영한 신경심리적 과제와의 상관성을 살 펴볼 수 있을 것이다.

중심 단어 : 단어유창성·노인 - 알츠하이머병 - 인지-언어·집행 기능.

\section{Ethical Statement}

This study was approved by the Institutional Review Board (\#HUGSAUD461850).

\section{Acknowledgments N/A}

\section{Declaration of Conflicting Interests}

There are no conflict interests.

\section{Funding} N/A

\section{Author Contributions}

All authors contributed equally to this work. M.L. designed and performed experiments, analyzed data, wrote the paper, and provided statistical analysis and critical revision; B.K. performed experiments in the clinic and provided critical revision. Also, the authors discussed the results together and implications and commented on the manuscript at each stage.

\section{ORCID iDs}

Mi Sook Lee

Bo Seon Kim

\section{https://orcid.org/0000-0001-9255-565X}

https://orcid.org/0000-0002-8351-1417

\section{REFERENCES}

Amieva, H., Phillips, L. H., Della Sala, S., \& Henry, J. D. (2004). Inhibitory functioning in Alzheimer's disease. Brain, 127(Pt 5), 949-964.

Andrés, P. \& Van der Linden, M. (2002). Are central executive functions working in patients with focal frontal lesions? Neuropsychologia, 40(7), 835-845.

Baddeley, A. (2000). The episodic buffer: A new component of working memory? Trends in Cognitive Sciences, 4(11), 417-423.

Benjamin, M. J., Cifelli, A., Garrard, P., Caine, D., \& Jones, F. W. (2015). The role of working memory and verbal fluency in autobiographical memory in early Alzheimer's disease and matched controls. Neuropsychologia, $78,115-121$.

Birn, R. M., Kenworthy, L., Case, L., Caravella, R., Jones, T. B., Bandettini, P. A., et al. (2010). Neural systems supporting lexical search guided by letter and semantic category cues: A self-paced overt response fMRI study of verbal fluency. Neuroimage, 49(1), 1099-1107.

Choi, H. J. (2012). Performances of verbal fluency task in normal elderly: Effects of gender and educational level by categories. Journal of Speech and Hearing Disorders, 21(2), 37-52.

Dennis, N. A. \& Cabeza, R. (2008). Neuroimaging of healthy cognitive aging. In Craik, F. I. M. \& Salthouse, T. A. (3rd ed.). The Handbook of Aging and Cognition (pp. 2001-2054). New York, NY: Psychology Press.

de Paula, J. J. \& Malloy-Diniz, L. F. (2013). Executive functions as predictors of functional performance in mild Alzheimer's dementia and mild cognitive impairment elderly. Estudos de Psicologia, 18(1), 117-124.

Henry, J. D., Crawford, J. R., \& Phillips, L. H. (2004). Verbal fluency performance in dementia of the Alzheimer's type: A meta-analysis. Neuropsychologia, 42(9), 1212-1222.

Hull, R., Martin, R. C., Beier, M. E., Lane, D., \& Hamilton, A. C. (2008). Executive function in older adults: A structural equation modeling approach. Neuropsychology, 22(4), 508-522.

Ivanoiu, A., Cooper, J. M., Shanks, M. F., \& Venneri, A. (2006). Patterns of impairment in autobiographical memory in the degenerative dementias constrain models of memory. Neuropsychologia, 44(10), 1936-1955.

Kang, Y. W. (2006). A normative study of the Korean-Mini Mental State Examination (K-MMSE) in the elderly. Korean Journal of Psychology: General, 25(2), 1-12.

Kang, Y. W., Chin, J. H., Na, D. L., Lee, J. H., \& Park, J. S. (2000). A normative study of the Korean version of Controlled Oral Word Association Test (COWAT) in the elderly. Korean Journal of Clinical Psychology, 19(2), 385-392.

Kim, H. \& Kim, S. R. (2013). Development of short form of the Korean version-the Boston Naming Test (K-BNT-15) based on item response theory. The Journal of the Korea Contents Association, 13(12), 321-327.

Laatu, S., Revonsuo, A., Jäykkä, H., Portin, R., \& Rinne, J. O. (2003). Visual object recognition in early Alzheimer's disease: Deficits in semantic processing. Acta Neurologica Scandinavica, 108(2), 82-89.

Laws, K. R., Adlington, R. L., Gale, T. M., Moreno-Martínez, F. J., \& Sartori, G. (2007). A meta-analytic review of category naming in Alzheimer's disease. Neuropsychologia, 45(12), 2674-2682.

Lee, J. H., Kang, Y. W., Jin, J. H., Na, D. L., \& Park, J. S. (2000). A normative study of the Korean version of Controlled Oral Word Association Test (COWAT) in the elderly. Korean Journal of Clinical Psychology, 19(2), 385-392.

Lee, M. S (2013). Development and application of cognitive-pragmatic language ability assessment protocol for traumatic brain injury (CAPTBI). (Unpublished doctoral dissertation). Yonsei university, Seoul.

Lee, M. S. (2016). Correlation between pragmatic language and executive function in patients with acquired brain injury. The Journal of the Korea Contents Association, 16(5), 58-67.

Lee, M. S. \& Kim, H. (2011). Characteristics of expressive language in normal aging, mild cognitive impairment, and Alzheimer's disease. Dementia and Neurocognitive Disorders, 10, 69-79.

Marczinski, C. A. \& Kertesz, A. (2006). Category and letter fluency in semantic dementia, primary progressive aphasia, and Alzheimer's disease. Brain and Language, 97(3), 258-265.

McDowd, J., Hoffman, L., Rozek, E., Lyons, K. E., Pahwa, R., Burns, J., et al. (2011). Understanding verbal fluency in healthy aging, Alzheimer's disease, and Parkinson's disease. Neuropsychology, 25(2), 210-225.

McKhann, G., Drachman, D., Folstein, M., Katzman, R., Price, D., \& Stadlan, E. M. (1984). Clinical diagnosis of Alzheimer's disease: Report of the NINCDS-ADRDA Work Group under the auspices of Department of Health and Human Services Task Force on Alzheimer's Disease. Neurology, 34(7), 939-944. 
Morris, J. C. (1993). The Clinical Dementia Rating (CDR): Current version and scoring rules. Neurology, 43(11), 2412-2414.

Park, M. S. \& Chey, J. Y. (2003). A normative study of the modified Trail Making Test for elderly Korean people. The Korean Journal of Clinical Psychology, 22(1), 247-259.

Peach, R. K. \& Shapiro, L. P. (2012). Cognition and Acquired Language Disorders: An Information Processing Approach. (1st ed.). Maryland Heights, MO: Mosby.

Raz, N. (2005). The aging brain observed in vivo: Differential changes and their modifiers. In Cabeza, R., Nyberg, L., \& Park, D. Cognitive Neuroscience of Aging: Linking Cognitive and Cerebral Aging (pp. 19-57). New York, NY: Oxford University Press.

Rosen, V. M., Sunderland, T., Levy, J., Harwell, A., McGee, L., Hammond, C., et al. (2005). Apolipoprotein E and category fluency: Evidence for reduced semantic access in healthy normal controls at risk for developing Alzheimer's disease. Neuropsychologia, 43(4), 647-658.

Royall, D. R., Palmer, R., Chiodo, L. K., \& Polk, M. J. (2004). Declining executive control in normal aging predicts change in functional status: The Freedom House Study. Journal of the American Geriatrics Society, 52(3), 346-352.

Salis, C. (2012). Short-term memory treatment: Patterns of learning and generalisation to sentence comprehension in a person with aphasia. Neuropsychological Rehabilitation, 22(3), 428-448.

Salthouse, T. A. (2005). Relations between cognitive abilities and measures of executive functioning. Neuropsychology, 19(4), 532-545.

Salthouse, T. A., Atkinson, T. M., \& Berish, D. E. (2003). Executive functioning as a potential mediator of age-related cognitive decline in normal adults. Journal of Experimental Psychology: General, 132(4), 566-
594.

Seniów, J., Litwin, M., Litwin, T., Leśniak, M., \& Członkowska, A. (2009). New approach to the rehabilitation of post-stroke focal cognitive syndrome: Effect of levodopa combined with speech and language therapy on functional recovery from aphasia. Journal of the Neurological Sciences, 283(1-2), 214-218.

Shin, J. (2008). Phoneme and syllable frequencies of Korean based on the analysis of spontaneous speech data. Communication Sciences and Disorders, 13(2), 193-215.

Shin, J. (2010). Phoneme and syllable frequencies based on the analysis of entries in the Korean dictionary. Communication Sciences and Disorders, 15(1), 94-106.

Signorini, M. \& Volpato, C. (2006). Action fluency in Parkinson's disease: A follow-up study. Movement Disorder, 21(4), 467-472.

Tchakoute, C. T., Sainani, K. L., \& Henderson, V. W.; Raloxifene in Alzheimer's Disease Investigators. (2017). Semantic memory in the clinical progression of Alzheimer disease. Cognitive and Behavioral Neurology, 30(3), 81-89.

Unsworth, N., Spillers, G. J., \& Brewer, G. A. (2012). The role of working memory capacity in autobiographical retrieval: Individual differences in strategic search. Memory, 20(2), 167-176.

Vukovic, M., Vuksanovic, J., \& Vukovic, I. (2008). Comparison of the recovery patterns of language and cognitive functions in patients with post-traumatic language processing deficits and in patients with aphasia following a stroke. Journal of Communication Disorders, 41(6), 531552.

Yeom, T., Park, Y., Oh, K., Kim, J., \& Lee, Y. (1992). A Manual for K-WAIS. Seoul: Korea Psychology. 